\title{
B-Type Natriuretic Peptide Predict Mortality in Diabetic Patients with Foot Ulcer
}

\author{
Ezio Faglia ${ }^{1}$, Giacomo Clerici ${ }^{1}$, Maurizio Caminiti ${ }^{1}$, Curci Vincenzo ${ }^{1}$, \\ Alberto Morabito ${ }^{2}$, Vincenzo Prisco ${ }^{3}$, Marco Prisco ${ }^{3}$, Rosaria Greco ${ }^{3}$ and \\ Michael Edmonds ${ }^{4}$ \\ ${ }^{1}$ Diabetic Foot Center - IRCCS Multimedica, Sesto San Giovanni (Milan), Italy \\ ${ }^{2}$ Medical statistic Unit - University of Milan, Italy \\ ${ }^{3}$ Fondazione DeaMedicaOnlusPagani (Italy) \\ ${ }^{4}$ King's College Hospital, London (UK)
}

Correspondence should be addressed to: Giacomo Clerici; giacomo.clerici@multimedica.it

Received 2 October2013; Accepted 18November 2013; Published 31 December 2013

Academic Editor: Nikolaos Papanas

Copyright (C) 2013 Ezio Faglia, Giacomo Clerici, Maurizio Caminiti, Curci Vincenzo, Alberto Morabito, Vincenzo Prisco, Marco Prisco, Rosaria Greco and Michael Edmonds. Distributed under Creative Commons CC-BY 3.0

\begin{abstract}
The background of this article is to retrospectively investigate the role of B-type natriuretic peptide (BNP) levels as an independent prognostic marker for mortality in diabetic patients with foot ulcer.

In the period 1 January-30 June 2009, 279 diabetic patients were admitted to our foot center because of foot ulcer: neuroischemic in 182 (65.2\%), neuropathic in 97 (34.8\%), infected in 233 $(83.5 \%)$. In all patients BNP (normal value: $\leq 100 \mathrm{pg} / \mathrm{mL}$ ) was evaluated at admission.

Mortality from any cause was established and the relationship between the recorded variables and risk of death was evaluated by the survival Cox regression model. Kaplan-Meier analysis was performed. BNP was $>100 \mathrm{pg} / \mathrm{mL}$ in 167 (59.9\%) patients. 278 (99.6\%) patients were followed to December 31, 2012 with a mean follow-up of $3.6 \pm 0.2$ years.

Seventy-one/278 (25.5\%) patients died. Of these, $61(85.9 \%)$ had a BNP value $>100 \mathrm{pg} / \mathrm{mL}$. Forty-five/71 (63.4\%) patients died from cardiac cause. The most frequent cause of death was heart disease: $45 / 71$ (63.4\%). Of these, 24 patients had no history of CAD.

Multivariate analysis showed the independent predictors of death to be BNP > 100 (hazard ratio 6.040; $\mathrm{p}<0.001 ; \mathrm{CI}, 2.380-15.328$ ), age (hazard ratio 1.043, $\mathrm{p}=0.024, \mathrm{CI} 1.001-1.082$ ), and dialysis treatment (hazard ratio $3.145 ; \mathrm{p}=0.032 ; \mathrm{CI}, 1.100-8.988$ ).
\end{abstract}

Cite this Article as: Ezio Faglia, Giacomo Clerici, Maurizio Caminiti, Curci Vincenzo, Alberto Morabito, Vincenzo Prisco, Marco Prisco, Rosaria Greco and Michael Edmonds (2013), "B-Type Natriuretic Peptide Predict Mortality in Diabetic Patients with Foot Ulcer," Journal of Research in Diabetes, Vol. 2013 (2013), Article ID 388970, DOI: 10.5171/2013.388970 
In diabetic patients with foot ulcer an elevated BNP level is a strong predictor of the excess mortality, independent of history of cardiac disease.

Keywords: Diabetic foot ulcer, b-type natriuretic peptide, all-cause mortality, history of cardiac disease, cardiac mortality.

\section{Introduction}

Several observational studies have suggested a high mortality rate in patients with diabetic foot ulceration (DFU) $(1,2)$. Increased risk of mortality is usually ascribed to a high incidence of cardiovascular morbidity in patients with neuroischemic foot $(3,4)$. Although increased mortality in diabetic patients with neuropathic foot ulcer has received some attention, the identification of highrisk patients remains a priority $(5,6)$. Measurement of markers which predict excess mortality might improve the prediction of adverse outcome in this population of patients.

B-type natriuretic peptide (BNP) level is an independent marker both of cardiovascular outcome and also of all cause mortality beyond conventional cardiovascular risk factors $(7,8)$.

In 1999 we started to determine the BNP in diabetic patients admitted to our institution because of a foot ulcer as a marker of increased risk of mortality in patients undergoing foot surgery. Having been very low mortality in the early period the determination of BNP for this purpose has been suspended. However, we followed these patients over time.

We aimed to investigate the role of BNP levels as an independent prognostic marker for all-cause mortality in diabetic patients with foot ulcer.

\section{Patients and Methods}

\section{Data Collection}

This is a retrospective study of diabetic patients admitted because of foot ulcer in thr Diabetic Foot Centre in Multimedica Hospital, Sesto S. Giovanni, Italy. The data presented derived from the data base of

\section{Protocol}

In all diabetic patients referred to our diabetic foot center for foot ulcer the severity of lesion was graded using the University of Texas Wound Classification System (9). All patients were assessed for the presence of diabetic sensory neuropathy and/or critical limb ischemia (CLI). Sensory neuropathy was detected if vibration perception threshold was $>25 \mathrm{~V}$ and sensitivity was absent in $>5 / 9$ foot points at Semmes-Weinstein $10 \mathrm{~g}$ filament. CLI was detected using the TASC II criteria of non invasive parameters: transcutaneous oxygen tension (TcPO2; TCMTM3, Radiometer GMBH, Copenhagen, Denmark) at the dorsum of the foot was < $30 \mathrm{mmHg}$ and ankle pressure $<70 \mathrm{mmHg}$ when measurable (absent foot pulses or non-compressible foot arteries were due to medial calcifications) with a continuous wave Doppler instrument (DIADOP 50, Mediland s.r.l. Varedo, Milan, Italy) (10). All patients with CLI were referred for an angiographic study and peripheral angioplasty (PTA) or bypass graft (BPG) was performed. After revascularization antithrombotic therapy with ticlopidine $500 \mathrm{mg}$ plus acetyl salicic acid $100 \mathrm{mg}$ was prescribed indefinitely or was confirmed if already used.

The foot lesion was treated with surgical intervention and/or dressing (11)

For each patient, all of the following variables were recorded: gender and age; duration and treatment of diabetes; history of cardiac disease, stroke, arterial hypertension and diabetic retinopathy. In this study blood glucose level $(\mathrm{mg} / \mathrm{dl})$, glycosylated hemoglobin (HbA1c, $\mathrm{Hb} \%$, high pressure liquid chromatography, normal value: 4-6.4),serum creatinine value (mg/dl, Jaffe, Roche, Milan, Italy), arterial systolic and diastolic values, Creactive protein (CRP, $\mathrm{mg} / \mathrm{dL}$ ulti med 
Products - Deutschland), total cholesterol (colorimetry, Boehringer Mannheim, Monza, Italy), high-density lipoprotein cholesterol (HDL, Polyethylene Glycol 6000 , reagent made in laboratory), triglycerides (colorimetry, Bayer, Milan Italy).were measured on admission.

Plasma concentrations of BNP were measured by a sandwich immunoassay on an ADVIA Centaur ${ }^{\circledR} \quad$ XP Immunoassay System (Siemens Healthcare Diagnostics Milan, Italy)

After hospital discharge all the patients with foot ulcer were examined at our center until complete ulcer healing occurred. Our Institute is a tertiary diabetic foot center: patients were referred to our center from other hospitals and once healed, they were moved to their original center, for the control of diabetes and treatment of comorbid conditions. All data regarding vital status and cause and date of death were obtained from clinicians managing these patients.

\section{Follow-Up}

The vital status of 278 followed patients was determined at the end of follow-up and dates and causes of deaths were recorded. After hospital discharge all the patients with foot ulcer were examined at our Centre until complete ulcer healing occurred. Patients were examined once year in our Centre and vital status was recorded in this moment. All the data regarding patients who did not attend at follow-up visit were obtained from the colleagues treating these patients.

\section{StatisticAnalysis}

This is a retrospective study. We considered the consecutive series of patients as a cohort study and reported the descriptive statistics as average values and standard deviation for the continuous variables and as percentages and contingency tables for the qualitative and discrete variables. The $95 \%$ level was been adopted to build up the confidence intervals and 5\% level has been considered to test the null hypotheses. The time and status of each patient from the date of enrolment to the foot ulcer and death was been studied by applying the Kaplan-Meier approach and the product/ limit curve was built up. The relationship between the recorded variables and risk of death was evaluated by the survival Cox regression model and the data were reported by hazard ratio (HR) and 95\% confidence interval (CI). Stata 10.0 (Statistics/Data Analysis, Stata Corporation, 4905 Lakeway Drive, College Station, Texas, USA) was used for calculations.

\section{Results}

In the period 1 January-30 June 2009, 279 diabetic patients have been admitted in our foot center because of foot ulcer. The demographic and clinical characteristics of the study population are reported in Table 1. Revascularization was performed in 180 (98.9\%) of the 182 patients with CLI, in 159 with angioplasty, in 21 with bypass graft. In 2 patients revascularization was not possible either with angioplasty nor bypass graft. Major amputation occurred in 27 (9.7\%) patients.

BNP was $>100 \mathrm{pg} / \mathrm{mL}$ in $167 / 279$ (59.9\%) patients. 
Table 1:Demographic and Clinical Characteristics of Study Population ( $\mathrm{N}=279)$

\begin{tabular}{|c|c|}
\hline variable & \\
\hline Age (years) & $69.5 \pm 10.9$ \\
\hline Females/males (n) & $83(29.7 \%) / 196(70.3 \%)$ \\
\hline Insulin/oral therapy (n) & $199(71.3 \%) / 80(28.7 \%)$ \\
\hline Diabetes duration (years) & $18.9 \pm 12.3$ \\
\hline Admission glycemia (mg/dl) & $167.8 \pm 78.0$ \\
\hline Glycosylated hemoglobin (\% of hemoglobin) & $7.7 \pm 1.8$ \\
\hline Total cholesterol (mg/dl) & $155.3 \pm 47.2$ \\
\hline HDL cholesterol (mg/dl) & $39.4 \pm 16.9$ \\
\hline Triglycerides (mg/dl) & $137.2 \pm 74.3$ \\
\hline Current smokers (n) & $4(1.4 \%)$ \\
\hline Anti-hypertensive therapy (n) & $130(46.6 \%)$ \\
\hline Systolic blood pressure (mmHg) & $127,3 \pm 17.6$ \\
\hline Diastolic blood pressure ( $\mathrm{mmHg}$ ) & $70.9 \pm 9,1$ \\
\hline Retinopathy & $64(22.9 \%)$ \\
\hline Creatinine value $>130 \mathrm{mg} / \mathrm{dl}(\mathrm{n})$ & $106(40.0 \%)$ \\
\hline Dialysis (n) & $23(8.2 \%)$ \\
\hline History of coronary artery disease (n) & $93(33.3 \%)$ \\
\hline History of stroke (n) & $57(20.4 \%)$ \\
\hline Sensory motor neuropathy (n) & $273(97.8 \%)$ \\
\hline Critical limb ischemia (n) & $182(65.2 \%)$ \\
\hline $\mathrm{TcPO}_{2}$ before revascularization $(\mathrm{mm} / \mathrm{Hg})(\mathrm{n}=180)$ & $15.6 \pm 8.8$ \\
\hline $\mathrm{TcPO}_{2}$ after revascularization $(\mathrm{mm} / \mathrm{Hg})(\mathrm{n}=180)$ & $42.0 \pm 17.5$ \\
\hline Ankle pressure before revascularization $(\mathrm{mm} / \mathrm{Hg})(\mathrm{n}=180)$ & $74 \pm 36.6$ \\
\hline Ankle pressure after revascularization $(\mathrm{mm} / \mathrm{Hg})(\mathrm{n}=180)$ & $126.8 \pm 38.3$ \\
\hline Leucocytes count & $8940 \pm 3451$ \\
\hline C-reactive protein $(\mathrm{mg} / \mathrm{dL})$ & $5.01 \pm 6.18$ \\
\hline Infection of the ulcer (n) & $239(85.7 \%)$ \\
\hline Texas wound classification A-II (n) & 9 \\
\hline Texas wound classification A-III (n) & 16 \\
\hline Texas wound classification B-II (n) & 20 \\
\hline Texas wound classification B-III (n) & 52 \\
\hline Texas wound classification C-I (n) & 6 \\
\hline Texas wound classification C-II (n) & 9 \\
\hline Texas wound classification D-II (n) & 41 \\
\hline Texas wound classification D-III (n) & 126 \\
\hline
\end{tabular}

Data are $\mathrm{n}(\%)$ or mean $\pm 1 \mathrm{SD}$

Two hundred seventy-eight (99.6\%) were followed to december 31, 2012 with a mean follow-up of 3.6 ? 0.2 years.

Seventy-one/278 (26.5\%) patients died, one at 30 days, all other during follow-up.
Table 2 reports the cause of death. Sixtyone/71(85.9\%) patients who died had a BNP value $>100 \mathrm{pg} / \mathrm{mL}$. The Kaplan-Meier curves for the survival estimate by BNP > $100 \mathrm{pg} / \mathrm{mL}$ is reported in figure 1 . 


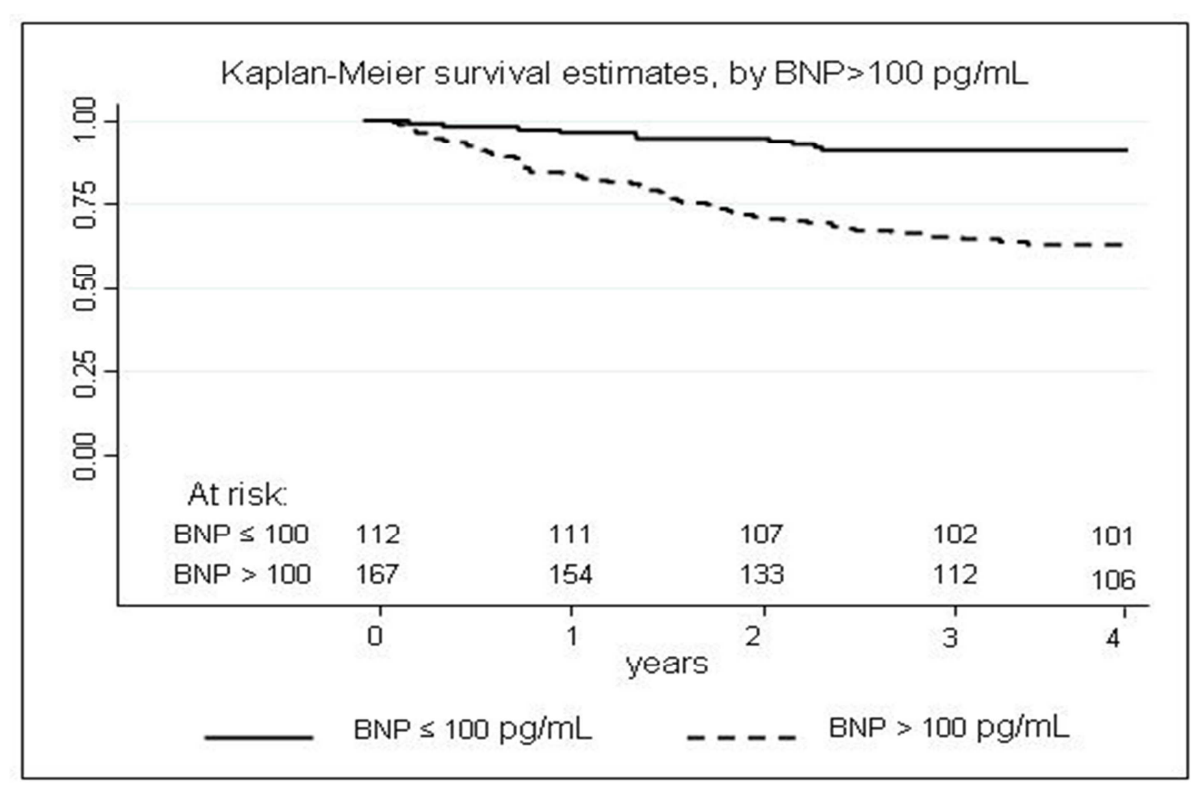

Fig 1. Kaplan-Meier Survival Estimate, by B-Type Natriuretic Peptide (BNP) Levels

Table 2:Causes of Death $(\mathrm{N}=71)$ in Followed Population $(\mathrm{N}=278)$

\begin{tabular}{|l|l|}
\hline cause of death & n (\%) \\
\hline cardiac disease & $45(63.4 \%)$ \\
\hline stroke & $4(6.5 \%)$ \\
\hline cancer & $4(6.5 \%)$ \\
\hline pulmonary embolism & $1(1.6 \%)$ \\
\hline abdominal aneurysm & $1(1.6 \%)$ \\
\hline renal insufficiency & $3(4.8 \%)$ \\
\hline peritonitis & $1(3.2 \%)$ \\
\hline gastric haemorrhage & $1(3.2 \%)$ \\
\hline pneumonia & $4(6.5 \%)$ \\
\hline Chronic obstructive pulmonary disease & $2(3.2 \%)$ \\
\hline geromarasmus & $2(4.8 \%)$ \\
\hline septic shock & $2(3.2 \%)$ \\
\hline unknown & $1(1.6 \%)$ \\
\hline
\end{tabular}

The most frequent cause of death was heart disease: $45 / 71(63.4 \%)$. Of the 45 patients died of cardiac causes, 24 patients had no history of CAD.

Univariate analysis results of the association with the variables considered and death are summarized in table 3 .
Multivariate analysis of the variables that were found to be associated with death in the univariate analysis demonstrated the independent role of age (hazard ratio $1.043, \mathrm{p}=0.024$, CI 1.001-1.082), dialysis (hazard ratio $3.145, \mathrm{p}=0.032$, CI 1.100 8.988), and $\mathrm{BNP}>100 \mathrm{pg} / \mathrm{mL}$ (hazard ratio $6.040, \mathrm{p}<0.001$, CI 2.380 -15.328). 
Table 3: UnivariateAnalysis Results of the Association with the Variables Considered and Death ( $=71$ ) in Study Population ( $=278)$

\begin{tabular}{|l|l|l|l|}
\hline VARIABLES & HR & p value & $\mathbf{9 5 \% ~ C I ~}$ \\
\hline Age (1 year) & 1.052 & $<0.001$ & $1.026-1.079$ \\
\hline Male Gender (n) & 1.113 & 0.674 & $0.677-1.830$ \\
\hline Insulin treatment (n) & 1.702 & 0.075 & $0.948-3.054$ \\
\hline Diabetes duration (1 year)) & 1.015 & 0.109 & $0.997-1.034$ \\
\hline At entry glycemia (1 mg/dL) & 0.999 & 0.398 & $0.995-1.002$ \\
\hline Glycosylated hemoglobin (\% of Hb) & 0.778 & 0.200 & $0.664-0.911$ \\
\hline Cardiac disease (n) & 1.923 & 0.006 & $1.206-2.957$ \\
\hline Stroke (n) & 1.776 & 0.027 & $1.067-3.613$ \\
\hline Total Cholesterol (1 mmol/L) & 1.001 & 0.794 & $0.993-1.001$ \\
\hline HDL Cholesterol (1 mmol/L) & 0.988 & 0.295 & $0.958-1.002$ \\
\hline Triglycerides (1 mmol/L) & 1.002 & 0.672 & $0.991-1.001$ \\
\hline Arterial hypertension (n) & 1.314 & 0.250 & $0.825-2.094$ \\
\hline Systolic Pressure (1 mmHg) & 0.99 & 0.991 & $0.982-1.021$ \\
\hline Diastolic Pressure (1 mmHg) & 1.00 & 0.884 & $0.953-1.062$ \\
\hline Sensory neuropathy (n) & 0.981 & 0.771 & $0.844-1.142$ \\
\hline Retinopathy (n) & 0.801 & 0.458 & $0.446-1.438$ \\
\hline Creatinine> $1.30 \mathrm{mg} / \mathrm{dl}(\mathrm{n})$ & 2.402 & 0.001 & $0.419-4.067$ \\
\hline Dialysis (n) & 5.352 & $<0.001$ & $2.707-10.592$ \\
\hline Critical limb ischemia & 1.956 & 0.018 & $0.120-3.411$ \\
\hline C-reactive protein (1 mg/dL) & 1.024 & 0.177 & $0.890-1.059$ \\
\hline Leucocytes count (n) & 1.023 & 0.459 & $0.963-1.088$ \\
\hline Texas wound classification D III (n) & 1.024 & 0.953 & $0.465-2.254$ \\
\hline Major amputation (n) & 0.468 & 0.155 & $0.118-1.403$ \\
\hline BNP >100 pg/mL (n) & 4.846 & $<0.001$ & $2.482-9.461$ \\
\hline
\end{tabular}

\section{Discussion}

Diabetic patients with foot ulcer have an excess risk of all-cause mortality (12). This data is well known for a long time (13), and a recent meta-analysis has confirmed this (14). Measurement of BNP has proved to be a very reliable marker in the diagnosis of heart failure (15) and is recommended in patients with symptoms of left ventricular dysfunction (16). Moreover BNP is a strong predictor of cardiovascular mortality and cardiovascular disease beyond conventional risk factors (17-19).

Very recently a number of studies have investigated the value of BNP in diabetes disease (20-24) but role of BNP in the prognosis of diabetic patients with foot ulcer has not been examined except after the use of hyperbaric oxygen therapy (25). This study has shown that patients with $\mathrm{BNP}>100 \mathrm{pg} / \mathrm{mL} \mathrm{mg} / \mathrm{dl}$ have a higher risk of all-cause mortality in patients with foot ulcer. An increased risk was found in aged and dialysis patients, and this is wellknown in the literature.

None of the characteristics related to foot care as infection (CRP; leucocytes number), class of Texas wound classification, revascularization procedures, are associated with mortality. Presence of critical limb ischemia is significantly associated with death at univariate analysis, but is not a result independent risk factor at multivariate analysis.

We did not observe an independent association of risk with history of heart disease ad admission, despite a significant association in univariate analysis. This finding may seem at odds with the reported data in the literature and in particular with the only known to us study on mortality risk, which was performed in type 2 diabetic patients (26).

This data is not easily interpreted. We must consider that elevated BNP is present in 
more than half of the patients without history of cardiac disease died from cardiac causes. One cause could be the presence of subclinical atherosclerosis in patients with elevated BNP value (27). One limitation of our study was not to have investigated a subclinical left ventricular hypertrophy or ischemic coronary disease $(28,29)$. However, also the above-mentioned study of Tarnow et al (26) did not carry out investigations beyond at resting electrocardiogram which has a notoriously low sensitivity.. However, since BPN has a strong prognostic power, an abnormal value of it could be the reason for starting with a more accurate heart diagnostic evaluation. A simple blood sample could identify asymptomatic patients and could justify more expensive cardiologic imaging tests. Actually, this must be demonstrated by a study "ad hoc".

In our study population only one patient died at 30 days and in the first months: therefore the ability of pre-operative BNP value to predict the at 30 days mortality has not been put to the test (30).

\section{Limitations ofthe Study}

This is a retrospective study with its limits. In particular, we did not analyze the presence of silent CAD with proper imaging tests. Then, we do not know if patients with no known CAD history had a silent CAD: it would have added these patients to the patients with CAD history. Again, we did not evaluate the presence of a subclinical left ventricular hypertrophy: in these patients BPN is an important marker.

\section{Conclusions}

These findings show that BNP is a strong predictor of mortality in diabetic patients with foot ulcer, not related to the etiology and cure of the foot lesion. Elevated BNP is present in many patients who died from cardiac causes but without history of heart disease: this may suggest the usefulness of early diagnosis of heart disease in these patients? It remains to show that this early diagnosis can then decrease mortality in these patients.

\section{Competing Interests}

The authors declare that they have no competing interests.

\section{Authors' Contributions}

Ezio Faglia and Giacomo Clerici: concept and design of the study.

Clerici Giacomo, Maurizio Caminiti, Curci Vincenzo: data collection.

Ezio Faglia and Alberto Morabito: statistical analysis.

Michael Edmonds has reviewed the manuscript

\section{Abbreviations}

DFU, Diabetic foot ulceration;

BNP, B-type natriuretic peptide;

CLI, critical limb ischemia;

PTA, peripheral angioplasty;

BPG, bypass graft;

CHD; cardiac heart disease

HR, hazard ratio;

CI; confidence interval;

\section{References}

1. Iversen, M. M., Tell, G. S., Riise, T., Hanestad, B. R., Østbye, T., Graue, M. \& Midthjell, K. (2209). "History of Foot Ulcer Increases Mortality among Individuals with Diabetes: Ten-Year Follow-Up of the Nord-Trøndelag Health Study, Norway," Diabetes Care 32:2193-2199.

2. Apelqvist, J., Larsson, J. \&Agardh, C. D. (1993). "Long-Term Prognosis for Diabetic Patients with Foot Ulcers," Journal of Internal Medicine 233:485491. 
3. Moulik, P. K., Mtonga, R. \& Gill, G. V. (2003). "Amputation and Mortality in New-Onset Diabetic Foot Ulcers Stratified by Etiology," Diabetes Care 26:491-494.

4. Pinto, A., Tuttolomondo, A., Di Raimondo, D., Fernandez, P., La Placa, S., Di Gati, M. \& Licata G. (2008). "Cardiovascular Risk Profile and Morbidity in Subjects Affected by Type 2 Diabetes Mellitus with and Without Diabetic Foot," Metabolism 57:676-682.

5. Chammas, N. K., Hill, R. L. R., Foster, A. V. M. \& Edmonds, M. E. (2002). "Is Neuropathic Ulceration the Key to Understanding Increased Mortality Due to Ischaemic Heart Disease in Diabetic Foot Ulcer Patients? A Population Approach Using a Proportionate Model," Journal of International Medical Research 30:553559.

6. Winkley, K., Stahl, D., Chalder, T., Edmonds, M. E. \& Ismail K. (2007). "Risk Factors Associated with Adverse Outcomes in a Population-Based Prospective Cohort Study of People with Their First Diabetic Foot Ulcer," Journal of Diabetes and its Complications 21:341-349.

7. Di Angelantonio, E., Chowdhury, R., Sarwar, N., Ray, K. K., Gobin, R., Saleheen, D., Thompson, A., Gudnason, V., Sattar, N. \&Danesh, J. (2009). "BType Natriuretic Peptides and Cardiovascular Risk: Systematic Review and Meta-Analysis of 40 Prospective Studies," Circulation 120:2177-2187.

8. Velagaleti, R. S., Gona, P., Larson, M. G. et al. (2010). "Multimarker Approach for the Prediction of Heart Failure Incidence in the Community," Circulation 26:1700-1706.

9. Armstrong, D. G., Lavery, L. A. \&Harkless, L. B. (1998). "Validation of a Diabetic Wound Classification System. The Contribution of Depth, Infection, and Ischemia to Risk of Amputation," Diabetes Care 21:855-859.

10. Norgren, L., Hiatt, W. R., Dormandy, J. A., Nehler, M. R. \& Harris, K. A. (2007). 'Fowkes FGR on Behalf of the TASC II Working Group,' Inter-Society Consensus for the Management of Peripheral Arterial Disease (TASC II), Eur J VascEndovascSurg 33 (Suppl):S73-S108.

11. Frykberg, R. G., Zgonis, T., Armstrong, D. G., Driver, V. R., Giurini, J. M., Kravitz, S. R., Landsman, A. S., Lavery, L. A., Moore, J. C., Schuberth, J. M., et al. (2006). "Diabetic Foot Disorders: A Clinical Practice Guideline (2006 Revision)," The Journal of Foot and Ankle Surgery. 45(5 Suppl):S1-66.

12. Young, M. J., Mccardle, J. E., Randall, L. E. \& Barclay, J. I. (2008). "Improved Survival of Diabetic Foot Ulcer Patients 1995-2008: Possible Impact of Aggressive Cardiovascular Risk Management," Diabetes Care 31:21432147.

13. Boyko, E. J., Ahroni, J. H., Smith, D. G. \&Davignon, D. (1996). "Increased Mortality Associated with Diabetic Foot Ulcer," Diabetic Medicine 13:967972.

14. Brownrigg, J. R. W., Davey, J., Holt, P. J., Davis, W. A., Thompson, M. M., Ray, K. K. \&Hinchliffe, R. J. (2012). "The Association of Ulceration of the Foot with Cardiovascular and All-Cause Mortality in Patients with Diabetes: A Meta-Analysis," Diabetologia 55:29062912.

15. Porapakkham, P., Porapakkham, P., Zimmet, H., Billah, B. \& Krum, H. (2010). "B-Type Natriuretic PeptideGuided Heart Failure Therapy: A MetaAnalysis," Archives of Internal Medicine 22;:507-514.

16. Dickstein, K., Cohen-Solal, A., Filippatos, G., Mcmurray, J. J., Ponikowski, P., Poole-Wilson, P. A., Strömberg, A., Van Veldhuisen, D. J.,

Ezio Faglia, Giacomo Clerici, Maurizio Caminiti, Curci Vincenzo, Alberto Morabito, Vincenzo Prisco, Marco Prisco, Rosaria Greco and Michael Edmonds (2013), Journal of Research in Diabetes, DOI: 
Atar, D., Hoes, A. W., Keren, A. et al. (2010). 'ESC Committee for Practice Guidelines (CPG). ESC Guidelines for the Diagnosis and Treatment of Acute and Chronic Heart Failure 2008: The Task Force for the Diagnosis and Treatment of Acute and Chronic Heart Failure 2008 of the European Society of Cardiology. Developed in Collaboration with the Heart Failure Association of the ESC (HFA) and Endorsed by the European Society of Intensive Care Medicine (ESICM),' European Heart Journal.29:2388-2442.

17. Kragelund, C., Grønning, B., Køber, L., Hildebrandt, P. \& Steffensen, R. (2005). "N-Terminal Pro-B-Type Natriuretic Peptide and Long-Term Mortality in Stable Coronary Heart Disease," New England Journal of Medicine 17;:666675.

18. Post, F., Weilemann, L. S., Messow, C. M., Sinning, C. \& Münzel, T. (2008). "BType Natriuretic Peptide as a Marker for Sepsis-Induced Myocardial Depression in Intensive Care Patients," Critical Care Medicine 36:3030-3037.

19. Kistorp, C., Raymond, I., Pedersen, F., Gustafsson, F., Faber, J. \& Hildebrandt, P. (2005). "N-Terminal Pro-Brain Natriuretic Peptide, C-Reactive Protein, and Urinary Albumin Levels as Predictors of Mortality and Cardiovascular Events in Older Adults," JAMA 6:1609-1616.

20. Mueller, T., Dieplinger, B., Poelz, W., Endler, G., Wagner, O. F. \& Haltmayer, M. (2009). "Amino-Terminal Pro-BType Natriuretic Peptide as Predictor of Mortality in Patients with Symptomatic Peripheral Arterial Disease: 5-Year Follow-Up Data from the Linz Peripheral Arterial Disease Study," Clinical Chemistry 55:68-77.

21. Welsh, P. \&Mcmurray, J. J. (2012). "BType Natriuretic Peptide and Glycaemia: An Emerging Cardiometabolic Pathway?," Diabetologia55:1240-1243.
22. Onodera, M., Nakamura, M., Tanaka, F. et al. (2012). "Plasma B-Type Natriuretic Peptide Is Useful for Cardiovascular Risk Assessment in Community-Based Diabetes Subjects," International Heart Journal 53:176181.

23. Seki, N., Nishimura, M., Matsumoto, T., Fukazawa, M. \&Kenmochi, T. (2013). "Relationship between BNP Level and Renal Function in Diabetic Nephropathy with Microalbuminuria," Journal of Diabetes and its Complications 27:92-97.

24. Tarnow, L., Hildebrandt, P., Hansen, B. V., Borch-Johnsen, K. \&Parving, H. H. (2005). "Plasma N-Terminal Pro-Brain Natriuretic Peptide as an Independent Predictor of Mortality in Diabetic Nephropathy," Diabetologia48:149155.

25. Yildiz, S., Uzun, G., Uz, O., Ipcioglu, O. M., Kardesoglu, E. \&Ozcan, O. (2008). "NTerminal Pro-B-Type Natriuretic Peptide Levels Increases after Hyperbaric Oxygen Therapy in Diabetic Patients," Clinical and Investigative Medicine 31:E231-235.

26. Tarnow, L., Gall, M. A., Hansen, B. V., Hovind, P. \&Parving, H. H. (2006). "Plasma N-Terminal Pro-B-Type Natriuretic Peptide and Mortality in Type 2 Diabetes," Diabetologia49:2256-2262.

27. Senmaru, T., Fukui, M., Tanaka, M. Sakabe, K., Ushigome, E., Asano, M., Yamazaki, M., Hasegawa, G. \& Nakamura, N. (2012). "N-Terminal ProBrain Natriuretic Peptide Could be a Marker of Subclinical Atherosclerosis in Patients with Type 2 Diabetes," Heart and Vessels 28:151-156.

28. Reinhard, H., Hansen, P. R., Wiinberg, N., et al. (2012). "NT-Probnp, Echocardiographic Abnormalities and Subclinical Coronary Artery Disease in High Risk Type 2 Diabetic Patients," Cardiovascular Diabetology 11:19-29. 
29. Turfan, M., Akyel, A., Bolayir, H. A., Vatankulu, M. A., Aktürk, M., Yetkin, I. \&Boyaci, B. (2012). "Correlation of the Myocardial Performance Index with Plasma B-Type Natriuretic Peptide Levels in Type 2 Diabetes Mellitus and Impaired Glucose Tolerance,"KardiologiaPolska 70:556562.

30. Ryding, A. D. S., Kumar, S., Worthington, A. M. \& Burgess, D. (2009). "Prognostic Value of Brain Natriuretic Peptide in Noncardiac Surgery: A Aeta-Analysis," Anesthesiology 111:311-319. 